\title{
A IMPROCEDÊNCIA LIMINAR DO PEDIDO COMO GARANTIDOR DA CELERIDADE PROCESSUAL, UMA ANÁLISE CRÍTICA AO NOVO CÓDIGO DE PROCESSO CIVIL
}

${ }^{1}$ Luís Fernando Centurião Argondizo

${ }^{2}$ Wellington Henrique Rocha de Lima

Resumo: A improcedência liminar do pedido é um dos institutos que sofreu grande modificação em sua conceituação e aplicabilidade com o advento do novo código de processo civil nacional, no transcorrer do presente pontuar-se-á as modificações traçando um breve paralelo entre os preceitos pretéritos e os hodiernos, ainda com a exposição das modificações e suas justificativas, demonstrando um maior dinamismo processual, que visa a integração de uma ordem jurídica adequada a todos os que buscam o amparo da tutela judicial.

Palavras-chave: Devido processo legal; Celeridade Processual; Efetivação da jurisdição; Improcedência liminar; Princípios do processo.

\section{THE IMPAIRMENT OF THE ORDER AS A GUARANTOR OF THE PROCESSUAL CELERY, A CRITICAL ANALYSIS TO THE NEW CIVIL PROCESS CODE}

\begin{abstract}
The preliminary dismissal of the application is one of the institutes that has undergone great modification in its conceptualization and applicability with the advent of the new code of national civil procedure, in the course of the present the modifications will be marked out by drawing a brief parallel between the previous precepts and the with the presentation of the modifications and their justifications, demonstrating a greater procedural dynamism, which aims at the integration of an adequate legal order for all those who seek the protection of judicial protection.
\end{abstract}

Keywords: Effectiveness of jurisdiction; Due process legal; Preliminary injunction; Principles of the process; Related searches.

\section{Introdução}

A improcedência liminar do pedido, é um dos institutos que sofreram sensível alteração com o advento do novo código de processo civil em 2015, pois ampliou-se a possibilidade de aplicação do instituto, o que em primeira análise traz uma imagem de propagação de insegurança.

\footnotetext{
${ }^{1}$ Advogado, Mestre em Direito Processual Civil e Cidadania - UNIPAR, Integrante do PIC/UNIPAR, Bolsista CAPES/PROSUP/UNIPAR, Docente da Pós-Graduação da UNIPAR, Docente dos Cursos de Graduação da UESPAR.

${ }_{2}^{2}$ Advogado, Mestrando em Direito Processual Civil e Cidadania - UNIPAR
}

Rev. de Processo, Jurisdição e Efetividade da Justiça | e-ISSN: 2525-9814 | Porto Alegre | v. 4 | n. 2 |

p. $100-114$ | Jul/Dez. 2018 
Tem-se importante a análise do tema, afinal, este ao ser aplicada põe fim a incursão jurisdicional da parte que buscou albergue no judiciário, sendo em primeiro momento visto como uma negativa da prestação jurisdicional, consequentemente, uma negativa a tentativa de alcance de direito material subjetivo do polo passivo da demanda, precocemente rejeitada.

O que veremos não condizer com a verdade, pois, com tal ação o judiciário, além de responder a pretensão a ele colocada, observa uma série de elementos e princípios processuais e de direitos fundamentais, pois dá ao cidadão resposta adequada e célere ao seu pedido, que não teria chance de produzir resultado diverso do já obtido, caso ocorresse tradicional desenvolvimento da lide, o que apenas geraria um custo desnecessário a parte, bem como, uma falsa esperança de solução diversa da que lhe é apresentada, em ocorrendo a confirmação da improcedência liminar.

Veremos que o tema, nada mais é que uma técnica em que se produz uma aceleração de julgamento (MONNERAT, 2012, p. 341), que tenta combater as demandas que versam sobre temas repetitivos, assim, trazem uma abreviação a seu trâmite, já que teriam condições de gerar uma decisão diversa da lançada liminarmente, como será detalhado em momento posterior.

Tentar-se-á incursionar sobre o instituto, com a realização de um breve panorama comparativo entre o diploma processual pretérito e o atual, ainda, pontuar detalhes que advieram com o nascer da nova lei processual, bem como, evidenciar a importância da formação adequada dos precedentes, com intenção de garantir a segurança jurídica necessária para que se tenha uma aceitação progressiva do instituto em comento.

\section{Necessidade da Atividade Jurisdicional Preliminar}

Muito se debate sobre a possível crueldade e omissão de prestação jurisdicional, quando da improcedência liminar de demandas, porém, a possibilidade de aplicação e confirmação de tal decisão é forma de garantir segurança jurídica a todos jurisdicionado.

Ademais, não se pode apegar-se apenas a esta possibilidade de atuação preliminar do judiciário, já que a possibilidade de atuação liminar do Juízo é condição de aplicação plena da justiça, ou a sua busca.

É sabido que existem condições mínimas para aceitação do petitório inicial de qualquer demanda, sendo inclusive estes requisitos possuidores de uma seção especial no 


\section{A IMPROCEDÊNCIA LIMINAR DO PEDIDO COMO GARANTIDOR DA CELERIDADE PROCESSUAL, UMA ANÁLISE CRÍTICA AO NOVO CÓDIGO DE PROCESSO CIVIL}

diploma processual, contando com três artigos (319 a 321), que versam exclusivamente sobre a obrigatoriedade de requisitos mínimos para aceitação da petição.

Sendo caso de atenção do magistrado a condição formal da petição e consequentemente a intenção de obtenção de tutela em razão do direito material pretendido.

Ainda, possível a determinação de correções de vícios, julgamento de pedidos liminares ou mesmo, se for o caso, o indeferimento liminar do pedido por motivos variados que serão pontuados e justificados pelo Juízo quando da sua decisão (MEDINA, 2017, p.538).

Desta feita, a necessidade de atuação preliminar do Poder Judiciário se faz sensata, na medida em que ao ser acolhido o ingresso processual da pretensão da parte, inicia-se uma marcha marcada pelos demais princípios processuais, que garantem uma adequada instrução e consequente trâmite processual, que gera em si uma dilação temporal para a obtenção de uma resposta a demanda, bem como, um dispêndio de forças do Poder Judiciário, tanto de ordem financeira, quanto de ordem organizacional, que poderia ser minimizada com a apreciação prévia da contenda.

Logicamente, a possibilidade de aplicação do instituto em estudo é limitado, o que traz uma segurança jurídica ao feito, já que em caso de não previsão poder-se-ia produzir decisões marcadas por intenções que não as da justiça.

\section{Breve Paralelo entre o CPC 1973 x CPC 2015}

Para melhor entendimento do grau comparativo proposto no presente momento, necessária a exposição dos dispositivos legais que previa e prevê a possibilidade de improcedência liminar da demanda, ao falar-se do CPC de 1973 e do CPC 2015, respectivamente, com isso expõe-se os artigos 285-A e 332 dos aludidos diplomas para contemplação e consequente análise.

Art. 285-A - CPC/73.

Quando a matéria controvertida for unicamente de direito e no juízo já houver sido proferida sentença de total improcedência em outros casos idênticos, poderá ser dispensada a citação e proferida sentença, reproduzindo-se o teor da anteriormente prolatada. (Incluído pela Lei $\mathrm{n}^{\circ}$ 11.277, de 2006)

$\S 1^{\circ}$ Se o autor apelar, é facultado ao juiz decidir, no prazo de 5 (cinco) dias, não manter a sentença e determinar o prosseguimento da ação. (Incluído pela Lei $\mathrm{n}^{\circ} 11.277$, de 2006)

Rev. de Processo, Jurisdição e Efetividade da Justiça | e-ISSN: 2525-9814 | Porto Alegre | v. 4 | n. 2 | p. $100-114$ | Jul/Dez. 2018 
$\S 2^{\circ}$ Caso seja mantida a sentença, será ordenada a citação do réu para responder ao recurso. (Incluído pela Lei no 11.277, de 2006)

Art. $332-\mathrm{CPC} / 2015$.

Nas causas que dispensem a fase instrutória, o juiz, independentemente da citação do réu, julgará liminarmente improcedente o pedido que contrariar: I - enunciado de súmula do Supremo Tribunal Federal ou do Superior Tribunal de Justiça;

II - acórdão proferido pelo Supremo Tribunal Federal ou pelo Superior Tribunal de Justiça em julgamento de recursos repetitivos;

III - entendimento firmado em incidente de resolução de demandas repetitivas ou de assunção de competência;

IV - enunciado de súmula de tribunal de justiça sobre direito local.

$\S 1$ o O juiz também poderá julgar liminarmente improcedente o pedido se verificar, desde logo, a ocorrência de decadência ou de prescrição.

$\S 20$ Não interposta a apelação, o réu será intimado do trânsito em julgado da sentença, nos termos do art. 241.

§ 3o Interposta a apelação, o juiz poderá retratar-se em 5 (cinco) dias.

$\S 4$ o Se houver retratação, o juiz determinará o prosseguimento do processo, com a citação do réu, e, se não houver retratação, determinará a citação do réu para apresentar contrarrazões, no prazo de 15 (quinze) dias.

Da leitura dos textos podemos observar sensível modificação quanto a possibilidade de prolação da sentença que determine a improcedência liminar do pedido, enquanto no momento anterior o magistrado estava preso a situação que verse sobre a questão de direito, sendo necessária a atuação do mesmo Juízo em prolação de sentença de total improcedência, em casos pretéritos idênticos.

Já que no cotejo anterior a decisão anteriormente emanada pelo mesmo Juízo serviria com fundamentação da nova decisão, o que ocorria através da transcrição daquela no novo processo em análise.

Tanto que a falta de observação estrita ao contido no art. 285-A do CPC/1973 era motivo que impunha a cassação da sentença que não estampasse em seu corpo a fundamentação pretérita que lhe dava origem, vejamos:

PROCESSUAL CIVIL. AGRAVO REGIMENTAL NO RECURSO ESPECIAL. POLICIAL MILITAR. AUXÍLIO-MORADIA. REJEIÇÃO LIMINAR DO PEDIDO. NÃO DEMONSTRADA A ALEGẢDA VIOLAÇÃO AO ART. 535 DO CPC. INCIDÊNCIA DA SÚMULA 284/STF. FALTA DE PREQUESTIONAMENTO DO ART. 244 DO CPC. INCIDÊNCIA DA SÚMULA 211/STJ. JULGAMENTO LIMINAR DE MÉRITO. MEDIDA EXCEPCIONAL. IMPRESCINDÍVEL A PRESENÇA CONCOMITANTE DOS REQUISITOS LEGAIS. A DESATENÇÃO AOS PRESSUPOSTOS DO ART. 285-A DO CPC ACARRETA À CASSSAÇÃO DA SENTENÇA. AGRAVO REGIMENTAL DESPROVIDO. 
[...] 3. O julgamento liminar de mérito previsto no art. 285-A do CPC é medida excepcional, admitida apenas quando presentes, concomitantemente, os requisitos elencados no referido dispositivo. A aplicação do aludido comando legal está adstrita às hipóteses em que a matéria controvertida for exclusivamente de direito e que no juízo já houver sido proferida sentença de total improcedência em casos idênticos; ademais, não basta a mera menção às sentenças anteriormente prolatadas, sendo necessária a reprodução dos paradigmas.

4. A desatenção aos requisitos do art. 285-A do CPC impõe a cassação da sentença e a baixa dos autos para regular processamento da ação.

5. Agravo Regimental desprovido.

(AgRg no REsp 1177368/RJ, Rel. Ministro NAPOLEÃO NUNES MAIA FILHO, QUINTA TURMA, julgado em 03/02/2011, DJe 21/02/2011, grifo nosso)

O modelo antigo gerava grande debate e insegurança, pois possibilitava a atuação de entendimentos contrários os adotadas nas Cortes Superiores, pois impunha necessidade de utilização de entendimento do mesmo Juízo, o que, per si, fomentava um sentimento de insegurança jurídica, e afrontando diretamente a isonomia processual, a ordem hierárquica dos tribunais, bem como, o modelo hodierno de formação de precedente judiciais. (ARRUDA ALVIM; MEDINA; WAMBIER, 2007, p. 65-66)

Tanto que em primeira tentativa de se garantir o mínimo da segurança jurídica ao jurisdicionado o Superior Tribunal de Justiça acolheu entendimento de que as decisões proferidas pelos Juízos inferiores deveriam observância aos entendimentos lançados pelos Tribunais Superiores, que fora posteriormente exposto em informativo ${ }^{3}$, sendo da lavra do Ministro Luís Felipe Salomão, o voto que embasa tal entendimento, quando relatou o REsp 1109398/MS, proferindo decisão com a seguinte ementa:

DIREITO PROCESSUAL CIVIL. IMPROCEDÊNCIA PRIMA FACIE. ART. 285-A DO CPC. ENTENDIMENTO DO JUÍZO SENTENCIANTE. DISSIDÊNCIA RELATIVA ÀS INSTÂNCIAS SUPERIORES. APLICAÇÃO DA NOVA TÉCNICA. DESCABIMENTO. EXEGESE TELEOLÓGICA.

1. A aplicação do art. 285-A do CPC, mecanismo de celeridade e economia processual, supõe alinhamento entre o juízo sentenciante, quanto à matéria repetitiva, e o entendimento cristalizado nas instâncias superiores, sobretudo junto ao Superior Tribunal de Justiça e Supremo Tribunal Federal.

2. Recurso especial não provido.

\footnotetext{
${ }^{3}$ Informativo 477 do STJ.
} 
(REsp 1109398/MS, Rel. Ministro LUIS FELIPE SALOMÃO, QUARTA TURMA, julgado em 16/06/2011, DJe 01/08/2011, grifo nosso)

Entendimento que fora maturado posteriormente pela Ministra Nancy Andrigui quando do julgamento do REsp 1225227/MS, que previu a necessidade de ocorrência da dupla conformidade para acolhida de aplicação do Art. 285-A do CPC/1973, sendo este feito também, tratado em informativo de jurisprudencia ${ }^{4}$.

DIREITO PROCESSUAL CIVIL. RECURSO ESPECIAL. AÇÃO REVISIONAL DE CONTRATO BANCÁRIO. SENTENÇA LIMINAR DE IMPROCEDÊNCIA. ART. 285-A DO CPC. NECESSIDADE DE CONFORMIDADE COM O ENTENDIMENTO DO TRIBUNAL LOCAL E DOS TRIBUNAIS SUPERIORES.

1. Sentença de improcedência proferida com fulcro no art. 285-A do CPC que, embora esteja em consonância com a jurisprudência do STJ, diverge do entendimento do Tribunal de origem.

2. O art. 285-A do CPC constitui importante técnica de aceleração do processo.

3. É necessário, para que o objetivo visado pelo legislador seja alcançado, que o entendimento do Juiz de $1^{\circ}$ grau esteja em consonância com o entendimento do Tribunal local e dos Tribunais Superiores (dupla conforme).

4. Negado provimento ao recurso especial.

(REsp 1225227/MS, Rel. Ministra NANCY ANDRIGHI, TERCEIRA TURMA, julgado em 28/05/2013, DJe 12/06/2013, grifo nosso)

Assim, inegável que o trazido pelo art. 285-A do CPC/1973, não possuía consonância pratica com a intenção do Poder Judiciário de formação de precedentes jurisdicionais, já que possibilitava tanto um entendimento local de determinada matéria, quanto a inconformidade jurisprudencial no mesmo tribunal.

Afinal, possibilitar-se-ia ao Juízo de primeira instância proferir julgamento conflitante com os tribunais superiores, o que impunha barreira de uniformização de um entendimento do direito, de uma previsibilidade e da segurança jurídica que é dever do Poder Judiciário.

Já que o dispositivo poderia servir ao contrário da previsão legal, já que o modelo lançado pelo art. 285-A do CPC/1973, possibilitava lançamento de entendimento diversos, até mesmo na mesma Comarca, já que ao fundamentar a decisão de improcedência com uma decisão do mesmo Juízo, a limitação da segurança jurídica se dava ao jurisdicionado que

\footnotetext{
${ }^{4}$ Informativo 524 do STJ.
}

Rev. de Processo, Jurisdição e Efetividade da Justiça | e-ISSN: 2525-9814 | Porto Alegre | v. 4 | n. 2 | p. $100-114$ | Jul/Dez. 2018 


\section{A IMPROCEDÊNCIA LIMINAR DO PEDIDO COMO GARANTIDOR DA CELERIDADE PROCESSUAL, UMA ANÁLISE CRÍTICA AO NOVO CÓDIGO DE PROCESSO CIVIL}

abrangia a competência do órgão julgador em primeiro grau, o que servia como fomentador de um tratamento não isonômico a população.

Guardadas proporções, não se pode deixar de observar que a intenção em gerar uma uniformização de entendimento dos tribunais, vai ao encontro, de modo especial, em se ter uma previsibilidade de conduta e do resultado da demanda, o que poderá servir como guia de conduta do jurisdicionado, que ao ter acesso e conhecimento de um entendimento pacificado refletirá, antes de iniciar uma incursão aventureira junto ao Judiciário.

Para Teresa Arruda Alvim e Bruno Dantas (2017, p. 520) o modelo antigo previsto no art. 285-A do CPC/1973 servia com propagador de litígios, na medida em que se possibilitava encontrar entendimentos diversos em instâncias diferentes de nossa organização judiciária.

O engessamento e a insegurança que imperava no diploma processual civil anterior foi rompido com a promulgação do novo códex, que impõe observâncias até então escanteadas pelo legislador e sentida pelo julgador e jurisdicionado.

Afinal, não se pode olvidar que o Poder Judiciário, em que pese a extensão continental de nosso país, é único, não sendo admissível que um mesmo Poder profira decisões controversas sobre situações idênticas, ocorridas em um mesmo contexto histórico, político e social, valendo observar nova lição de Teresa Arruda Alvim e Bruno Dantas, acerca da isonomia processual, atentemo-nos.

O princípio da isonomia significa, grosso modo, que todos são iguais perante lei, logo, a lei deve a todos tratar de modo uniforme e assim também (sob pena de esvaziar-se o princípio) devem fazer os tribunais, respeitando o entendimento tido por correto e decidindo de forma idêntica casos iguais, num mesmo momento histórico. (ARRUDA ALVIM; DANTAS, 2017, p. 124)

Urge obtemperar que a comento lançado acima, não infringe o princípio do livre convencimento motivado do Juiz, mas apenas, alerta para a importância de respeito aos entendimentos dos Tribunais Superiores, que buscam a criação de uma jurisprudência pacífica que se aplique a todo o jurisdicionado, independentemente do local da propositura da ação.

No contexto atual, abre-se a possibilidade de maior aplicação do instituto ao ampliarse as situações que embasam a condição de apontar a improcedência liminar do pedido, pois aceita-se com o advento do novo diploma processual civil, que as orientação jurisprudenciais 
firmadas em súmulas, julgamentos de casos repetitivos (MEDINA, 2017, p.544), nesta evidencia-se a importância da nova ferramenta processual os Incidentes de Resolução de Demandas Repetitivas (IRDR's), ou ainda, nos casos de assunção de competência, sendo todos estes referenciais válidos para a sustentação do possível indeferimento liminar.

Demonstra-se, assim, inegável avanço no contexto de aplicação do dispositivo em análise, pois a flexibilização da rigidez do modelo anterior era anseio antigo dos operadores do direito, afinal prender-se a condição de possibilidade de imposição da improcedência liminar ao Juízo julgador, não coadunava com o modelo de celeridade e de processo justo e adequado (CABRAL, 2016, p. 152).

Inobstante elencadas as possibilidades de maior aplicação das decisões dos tribunais superiores no que tange o assunto em debate, deve-se evidenciar o texto do $\S 1^{\circ}$, do art. 332, do CPC/2015, que impõe a possibilidade de declaração de improcedência liminar do pedido, quando da verificação da ocorrência da decadência ou da prescrição, feito que no diploma processual pretérito, previa-se o indeferimento da petição inicial, dando noção mais técnica e adequada ao processo.

Nesta seara, não podemos deixar de observar que em comparação do art. 332, com o exposto no art. 927, ambos do CPC/2015, que determinam a obrigatoriedade de observação pelo magistrado de uma lista de decisões que devem nortear seu subjetivismo decisório, notase que o rol do primeiro não contempla a integralidade de hipóteses lançada no rol do segundo o que nos remete a interpretar que este seja exemplificativo, sendo possível a adoção de decisões diversas da apresentadas no corpo do primeiro disposto, mas que contemplem a previsão do segundo (KOEHLER, 2015, p.100).

Da análise comparativa entre os dispositivos legais acima expostos, devemos observar que a previsão contida no art. 927 do CPC/2015, não pode ser interpretada de modo restritivo, sendo-o exemplificativo, já que não se poderia taxar exclusividade de tratamento a precedentes emanados do Supremo Tribunal Federal, nestes sentido a lição de Cassio Scarpinella Bueno, quando diz:

[...] o art. 332 é dispositivo que se harmoniza, portanto, com o art. 927 e com a vocação que aquele dispositivo - e, mais amplamente, o próprio CPC de 2015 - quer emprestar aos 'precedentes' dos Tribunais brasileiros, notadamente, mas não exclusivamente, os provenientes do Supremo Tribunal Federal e do Superior Tribunal de Justiça. (BUENO, 2017, p. 360) 


\section{A IMPROCEDÊNCIA LIMINAR DO PEDIDO COMO GARANTIDOR DA CELERIDADE PROCESSUAL, UMA ANÁLISE CRÍTICA AO NOVO CÓDIGO DE PROCESSO CIVIL}

A lição alhures exposta é corroborada pelo próprio CPC/2015, que em seu art. 926, $\S \S 1^{\mathrm{o}}$ e $2^{\mathrm{o} 5}$, que serve de incentivo para que os Tribunais Regionais produzam suas súmulas que estampem sua jurisprudência dominante, tendo tais súmulas alcance em sua jurisdição de atuação, limitada a sua competência.

Ademais a possibilidade de aplicação que extravasa a questão unicamente de direito, pois com a regra advinda no CPC/2015 têm-se possível a prolação de sentença liminar de improcedência, dispensando-se a fase instrutória, o que alcança albergue na economia processual e na duração adequada do processo.

Nesse sentido, a lição de Aluisio Gonçalves de Castro Mendes e Larissa Clare Pachmann da Silva (2016), que demonstram a necessidade de observância de instauração de controvérsia quanto aso fatos em análise, vejamos:

Causa que dispensa a fase instrutória é aquela cuja matéria fática pode ser comprovada pela prova documental, já acostada aos autos. Havendo dúvida sobre os fatos, a disposição do art. 332 não pode ser aplicada. A nova redação do instituto afasta a problematicidade hermenêutica14 da redação do diploma de 1973, eis que matéria unicamente de direito não implicava a inexistência de um suporte fático à relação jurídica discutida, mas, sim, que eventual futura controvérsia que se desenvolveria, caso fosse citado o réu, não favoreceria o autor, pois o posicionamento judicial fixado estaria em desacordo com a pretensão autoral. (MENDES; SILVA, 2016)

No mesmo pensamento Fredie Didier Júnior (2015, p. 593), destaca a possibilidade de julgamento acerca da improcedência liminar do pedido, antes mesmo, da citação do Réu, desde que a conclusão pela improcedência seja evidente para o julgador, asseverando que “antecipa-se ainda mais o momento de julgamento da causa, dispensando não só a fase instrutória, mas também a própria ouvida do réu".

Ressaltando que o exposto alhures não se confunde com a impossibilidade jurídica do pedido, que encontrava-se expressa na versão pretérita do CPC pátrio, afinal por juridicamente possível considera-se a pretensão do autor quando esta não defrontasse com vedação legal (MEDINA, 1999, p.371-383).

\footnotetext{
${ }^{5}$ Art. 926, do CPC/2015 que diz:

Art. 926. Os tribunais devem uniformizar sua jurisprudência e mantê-la estável, íntegra e coerente. $\S 1^{\underline{0}} \mathrm{Na}$ forma estabelecida e segundo os pressupostos fixados no regimento interno, os tribunais editarão enunciados de súmula correspondentes a sua jurisprudência dominante.

$\S 2^{\circ}$ Ao editar enunciados de súmula, os tribunais devem ater-se às circunstâncias fáticas dos precedentes que motivaram sua criação.
}

Rev. de Processo, Jurisdição e Efetividade da Justiça | e-ISSN: 2525-9814 | Porto Alegre | v. 4 | n. 2 | p. $100-114$ | Jul/Dez. 2018 
Ademais a consagração do novo texto demonstra a intenção do judiciário em entregar uma resposta adequada a quem lhe procura, afinal, impor a parte um martírio processual, que contemple a produção de provas, debates, dispêndio de gastos, seja com custas processuais, ou mesmo com honorários advocatícios, em demandas que inegavelmente teriam seu resultado prejudicado pela existência de matéria pacificada junto aos tribunais superiores (DIDIER, 2015, p. 605), transgridem os princípios que se exige das partes do processo, quais sejam o modelo cooperativo de processo e a boa-fé objetiva de modo especial, pois ferir-se-ia estes princípios com a aceitação de um demanda que não teria razão de ser.

Assim, tem-se evidente que a possibilidade da declaração de improcedência liminar do pedido, não aflige os princípios norteadores do direito processual civil brasileiro, pois estes são respeitados e aplicados na decisão proferida, seja pelo seguimento do feito, ou mesmo na ocorrência do indeferimento.

Afinal, em caso de declaração de improcedência liminar, tal conduta, ainda, possibilitará ao demandante, em caso de seu desejo, levar sua pretensão e/ou tese jurídica aos tribunais competentes numa tentativa de modificação de seu entendimento, que em caso positivo poderá ser aplicado aos demais casos correlatos em nosso judiciário.

\section{A Jurisprudência como Referencial}

O art. 332 do CPC/2015 é claro quanto a possibilidade de rejeição liminar do pedido, quando a pretensão alcançar conteúdo defeso ou contrário a norma jurídica, quanto a este ponto, não existe controvérsia ou margem para uma possível problematização, pois ao invocar algo que lhe é defeso, não poderia a parte estar invocando uma possível lesão de direito.

Porém, o que pode se concatenar da previsão é definição de texto e norma, pois sabese que estes não se confundem, sendo possível delimitar que o texto é o ponto de partida para à norma, sendo esta formada pela interpretação oponível quando da resolução dos problemas (MEDINA, 2017, p. 79), sendo que estas deliberações possuem condição normativa, sendo oponíveis aos juízes subsequentes, imputando-lhes condão de obrigatoriedade (MACEDO, 2014, p. 303-327).

Dito isso, temos a norma como fonte de alimento e formação de opinião dos tribunais, sendo este expresso quando da edição das súmulas e nos julgamentos dos Incidentes de Resolução de Demandas Repetitivas (IRDR’s), cristalizando, assim, a possibilidade de que 


\section{A IMPROCEDÊNCIA LIMINAR DO PEDIDO COMO GARANTIDOR DA CELERIDADE PROCESSUAL, UMA ANÁLISE CRÍTICA AO NOVO CÓDIGO DE PROCESSO CIVIL}

o magistrado confirme a improcedência liminar, pois o pedido é nitidamente contrário a norma, cujo sentido está estampado em enunciado ou súmula, não sendo sensato asseverar que o pedido fora improcedente por ser contrário a súmula (MEDINA, 2017, p. 545).

Nesta senda de pensamento uma das novidades do CPC/2015 é o advento dos Incidentes de Resolução de Demandas Repetitivas (IRDR's), que insta consagrado nos arts. 976 e seguintes do diploma processual civil vigente e possuem pretensão de resolver a questão de direito que se põe em análise, através da fixação de uma tese jurídica que servirá como base para os casos futuros, nas palavras de Aluisio Gonçalves de Castro Mendes e Sofia Temer (2015), temos:

O incidente é uma das grandes apostas do novo diploma processual, cujo objetivo é firmar uma tese jurídica única aplicável a todos os casos repetitivos, a partir de um procedimento incidental em que se forme um modelo da controvérsia, conferindo prestação jurisdicional isonômica e previsível aos jurisdicionados e reduzindo o assoberbamento do Poder Judiciário com demandas seriadas. (MENDES; TEMER, 2015)

Desta feita, temos os Incidentes de Resolução de Demandas Repetitivas (IRDR's), como propagadores da jurisprudência, em uma comparação rasa, já que ao se decidir um destes incidentes, estar-se-á decidindo de modo indireto todas as demandas que estiverem sobrestadas aguardando seu julgamento.

Urge destacar que os Incidentes de Resolução de Demandas Repetitivas (IRDR's), são ferramentas que podem ser invocadas a partir da segunda instância, visando "[...]resolver coletivamente questões homogêneas de direito discutida de forma pulverizada nas demandas repetitivas[...]”, que integram a análise nos Tribunais Regionais, na lição de Marcos de Araújo Cavalcanti (2016, p. 38).

Desta feita, o entendimento ali determinado servirá como comando decisório para todos os casos pendentes de apreciação e futuros, que versem sobre os mesmos temas, inexistindo, com isso, instauração de dilação probatória.

Ademais resta evidente que a implantação do sistema de precedentes que é intentado pelo CPC/2015 é um grande avanço no contexto da pacificação processual, da uniformização das decisões e da segurança jurídica, porém, esta deve ser observada com as ressalvas necessárias, pois como toda e qualquer novidade na seara jurídica, esta também, carece de maturação e reflexão, tendo-se uma absorção gradual e sistêmica (MACEDO, 2015). 
Para um funcionamento adequado das instituições processuais, espera-se que as decisões que sejam convertidas em súmulas e enunciados, e consequentemente alimentem essas possíveis sentenças de improcedência liminar, dentre outras que encontram-se consagradas no texto do CPC/2015, estejam extremamente maturadas, sendo fruto de intensos debates, com a finalidade de esgotamento do assunto.

Tal pretensão se encontra acobertada pelo receio da tomada de decisão vinculativa que poderia gerar transtornos inegáveis ao jurisdicionado a que empunharia tal comando normativo.

Vale, ressaltar que a previsão de aplicação do entendimento dos tribunais superiores (CARREIRA ALVIM; CABRAL, 2008, p. 167), já era questão necessária para o julgamento de improcedência liminar, quando da vigência do CPC/73, sendo expresso pelo princípio da dupla conformidade, onde além de enquadrar-se no rol do artigo 285-A (MARINONI; ARENHART, 2010).

Com isso, tem-se por necessário a produção de entendimentos que serão transformados em súmulas ou enunciados, que estejam livres de ambiguidade e dotados de maturação plena, afinal, a exposição sumular ou de enunciado que possua condão de ambiguidade, deixará o magistrado, bem como, o jurisdicionado em dúvida quanto a interpretação adequada da norma, afinal, espera-se destas o esclarecimento necessário para sua aplicação e não a condição de margem interpretativa subjetiva das partes do processo.

Sendo que a ambiguidade também deve ser evitada pelo magistrado quando da prolação de sentença de improcedência liminar, afinal, caberá a ele identificar os fundamentos da súmula, enunciado ou IRDR cabível ao processo em análise, apresentando os porquês de sua decisão em consonância harmoniosa com as previsões do artigo 489, §1 ${ }^{\circ}, \mathrm{V}$ do CPC/2015 (MEDINA, 2017, p. 545).

\section{Considerações Finais}

A improcedência liminar do pedido, foi um dos institutos que sofreu grande modificação com o advento do CPC/2015, pois abriu-se o leque de possibilidades de aplicação do instituto, com a visualização de um rol mais abrangente de possibilidades.

Em que pese este rol ser exemplificativo, podendo ser concatenado com o previsto no art. 927, do mesmo diploma, a taxatividade textual prevendo a utilização das 


\section{A IMPROCEDÊNCIA LIMINAR DO PEDIDO COMO GARANTIDOR DA CELERIDADE PROCESSUAL, UMA ANÁLISE CRÍTICA AO NOVO CÓDIGO DE PROCESSO CIVIL}

manifestações pacíficas dos tribunais superiores como forma de possível solução da demanda de forma antecipada, foi ao encontro com o anseio dos operadores do direito, que já suplicavam por tal feito.

Apesar de que a dupla conformidade já fosse regra na condução dos processos no código pretérito, a segurança jurídica que se encontra com a previsão dá paz e segurança a todas partes do processo, pois têm não apenas uma expressão de vontade do magistrado, mas sim, a obediência linear imposta em enunciado ou súmula que emana de órgão superior.

Doutra banda, têm-se, ainda, a adequada e célere resposta do processo ao jurisdicionado, afinal, este não terá que percorrer os corredores judiciais em um martírio sem razão de ser, pois o único resultado possível para a demanda seria o julgamento de total improcedência ao final da instrução processual, pois se assim não o fizer, estará o magistrado confrontando entendimento dos órgãos superiores.

Ademais a improcedência liminar do pedido, possui ainda o condão da celeridade, mesmo quando declarada na demanda, afinal, pode a parte percorrer os caminhos dos tribunais superiores com sua tese na tentativa de modificação do entendimento válido até o momento, propiciando agilidade ao processo, pois este poderá ao passo da confirmação da improcedência iniciar a incursão ad quem, sem a necessidade de esperar-se pela instrução processual, que custaria tempo e dinheiro.

Com isso, demonstra-se a importância do instituto, bem como, das modificações que advieram com o CPC/2015, que seguiu neste o mesmo intentado no corpo do novo códex, primando pelos princípios processuais, na busca de entregar uma tutela justa e adequada aos anseios dos cidadãos, garantindo a atuação dos operadores do direito, cercados da segurança e da certeza do melhor ao processo.

\section{REFERÊNCIAS}

ARRUDA ALVIM, Teresa; MEDINA, José Miguel Garcia; WAMBIER, Luiz Rodrigues. Breves comentários à nova sistemática processual civil. v. 2. São Paulo: Revista dos Tribunais, 2007.

ARRUDA ALVIM, Teresa; DANTAS, Bruno. Recurso Especial, recurso extraordinário e a nova função dos tribunais superiores no direito brasileiro: (de acordo com o CPC de 2015 e a Lei 13.256/16). 4. ed. São Paulo: Revista dos Tribunais, 2017. 
BRASIL. Superior Tribunal de Justiça. Agravo Regimental no Recurso Especial n. 1177368/RJ. Relator Ministro Napoleão Nunes Maia Filho, 03 fev. 2011. Diário da Justiça [da] República Federativa do Brasil, Brasília, 21 fev. 2011.

Superior Tribunal de Justiça. Recurso Especial n. 109398/MS, Relator Ministro Luis Felipe Salomão, 16 jun. 2011. Diário da Justiça [da] República Federativa do Brasil, Brasília, 01 ago. 2011.

Superior Tribunal de Justiça. Recurso Especial n. 1225227/MS, Relatora Ministra Nancy Andrighi, 28 mai. 2013. Diário da Justiça [da] República Federativa do Brasil, Brasília, 12 jun. 2013.

BUENO, Cassio Scarpinella. Novo Código de Processo Civil anotado. 3. ed. São Paulo: Saraiva, 2017.

CABRAL, Trícia Navarro Xavier. A improcedência liminar do pedido e o saneamento do processo. Revista de Processo. São Paulo: Ed. RT, 2016, v. 252.

CARREIRA ALVIM, José Eduardo; CABRAL, Luciana Gontijo Carreira Alvim. Código de Processo Civil reformado. Comentários aos novos artigos, bem como, aos artigos alterados. 6. ed. Curitiba: Juruá, 2008.

CAVALCANTI, Marcos de Araújo. Incidente de resolução de demandas repetitivas (IRDR). São Paulo: Revista dos Tribunais, 2016.

DIDIER JÚNIOR, Fredie. Curso de direito processual civil: introdução ao direito processual civil, parte geral e processo de conhecimento. 17. ed. Salvador: Juspodivm, 2015.

KOEHLER, Frederio Augusto Leopoldino. As novidades do NCPC com relação à improcedência liminar do pedido (art. 285-A do CPC/73 (LGL\1973\5), atual art. 332 do NCPC). In: MACEDO, Lucas Buril de; PEIXOTO, Ravi; FREIRE, Alexandre (org.). Coleção novo CPC- Doutrina selecionada: Processo de conhecimento e disposições finais e transitórias. Salvador: Juspodivm, 2015, v. 2.

MACÊDO, Lucas Buril de. Contributo para a definição de ratio decidendi na teoria brasileira dos precedentes judiciais. Revista de Processo, São Paulo, v. 234, p.303-327, ago. 2014.

Precedentes judiciais e o direito processual civil. Salvador: Juspodivm, 2015.

MARINONI, Luiz Guilherme; ARENHART, Sérgio Cruz. Curso de processo civil. Processo de conhecimento. 8. ed. São Paulo: Revista dos Tribunais, 2010.

MEDINA, José Miguel Garcia. Curso de Direito processual civil moderno. 3. ed. São Paulo, Revista dos Tribunais, 2017.

Possibilidade Jurídica do Pedido e Mérito. Revista de Processo. São Paulo: Revista dos Tribunais, v. 93, p. 371-383, jan./mar. 1999. 


\section{A IMPROCEDÊNCIA LIMINAR DO PEDIDO COMO GARANTIDOR DA CELERIDADE PROCESSUAL, UMA ANÁLISE CRÍTICA AO NOVO CÓDIGO DE PROCESSO CIVIL}

MENDES, Aluisio Gonçalves de Castro; TEMER, Sofia. O incidente de resolução de demandas repetitivas do novo código de processo civil. Revista de Processo, São Paulo, v. 243, p. 283-331, mai. 2015.

MENDES, Aluisio Gonçalves de Castro; SILVA, Larissa Clare Pochmann da. O julgamento liminar de improcedência do pedido: a previsão do CPC/2015 (LGL/2015\1656) comparada à do CPC/1973 (LGL\1973\5). Revista de Processo, São Paulo, v. 261, p. 141-156, nov. 2016.

MONNERAT, Fábio Victor da Fonte. A jurisprudência uniformizada como estratégia de aceleração do procedimento. In: ARRUDA ALVIM WAMBIER, Teresa (Coord.). Direito jurisprudencial. São Paulo: Revista dos Tribunais, 2012. 